\title{
Ensaios preliminares em ratas wistar com extrato hidroetanólico de calunga (Simaba ferruginea St. Hil.) v.o., nas fases gestacionais de implantação, organogênese e período fetal: interferências na prole
}

\author{
VANZELER, M.L.A. ${ }^{* *}$; BARROS, W.M.2; NASELLO, A.G. ${ }^{3 ;}$ LOPES, L. ${ }^{1}$ \\ 'Universidade Federal de Mato Grosso (UFMT),- Faculdade de Medicina (FM), Departamento de Ciências \\ Básicas em Saúde (DCBS), Av. Fernando Correa da Costa, s/n. CEP: 78060-900 Cuiabá, MT-Brasil. "Instituto \\ Federal de Educação, Ciência e Tecnologia de Mato Grosso, (IFMT), Campus Cuiabá-Bela Vista, Av. Juliano

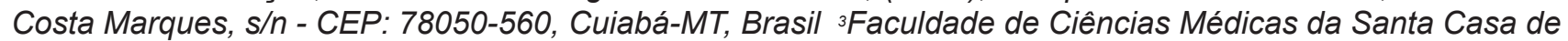 \\ São Paulo, Departamento de Ciências Fisiológicas, Rua Dr. Cesário Motta Jr., 61. CEP: 01221-020, São Paulo- \\ SP, Brasil. *Autor para correspondência: van.zeler@hotmail.com
}

\begin{abstract}
RESUMO: A susceptibilidade dos conceptos a agentes químicos varia muito em cada estágio do desenvolvimento. Devido a isto, a maioria dos países passou a exigir a análise do potencial para afetar todos os aspectos da reprodução (espermatogênese, acasalamento, prenhez, parto e lactação) para o desenvolvimento de novos medicamentos e fitoterápicos. O presente trabalho objetivou avaliar o efeito do extrato hidroetanólico de Simaba ferruginea St. Hil (calunga) (EHSF) v.o., em ratas da linhagem Wistar tratadas durante a prenhez e verificar a interferência no desenvolvimento intra-uterino da prole. As ratas foram tratadas com EHSF 50 e $100 \mathrm{mg} \mathrm{kg}^{-1}$ ou água destilada, do seguinte modo: a) do $1^{\circ}$ ao $6^{\circ}$ dia de prenhez (período da formação do blastocisto e implantação); b) do $8^{\circ}$ ao $16^{\circ}$ dia de prenhez (fase embrionária de organogênese); c) do $15^{\circ}$ ao $19^{\circ}$ dia de prenhez (fase do desenvolvimento fetal). $O$ tratamento do $1^{\circ}$ ao $6^{\circ}$ dia, mostrou redução no número de fetos com ambas doses e não alterou o peso do útero / ovário nem peso corporal das mães. Quando as ratas foram tratadas na fase da organogênese verificou-se, redução estatisticamente significante do número de fetos vivos com a dose $50 \mathrm{mg}$ $\mathrm{Kg}^{-1}$, e o aparecimento de fetos mortos em $30 \%$ das fêmeas tratadas com EHSF $50 \mathrm{mg} \mathrm{Kg}^{-1}$ e em $20 \%$ nas fêmeas tratadas com a dose de $100 \mathrm{mg} \mathrm{Kg}^{-1}$, não houve alteração no peso do útero / ovário nem no peso corporal das matrizes. Finalmente, o tratamento no período fetal não afetou o número de filhotes vivos, não provocou malformações anatômicas visíveis a olho nu, nem reabsorção fetal; porém, observou-se que $10 \%$ das mães tratadas com $50 \mathrm{mg} \mathrm{Kg}^{-1}$ apresentaram 2 fetos mortos e $20 \%$ das mães tratadas com $100 \mathrm{mg} \mathrm{Kg}^{-1}$ apresentaram, em média, 4 fetos mortos. Com estes dados, pode ser concluído que o EHSF apresenta baixa ou nenhuma toxicidade materna para ratas Wistar, embora seja letal para alguns descendentes, independente da fase da prenhez em que foram realizados os tratamentos maternos, sendo mais evidente nas fases precoces. Por este motivo, recomenda-se que esta planta não seja utilizada por mulheres grávidas.
\end{abstract}

Palavras-chave: Simaba ferruginea, ratas, prenhez, prole, Intra-uterino

\begin{abstract}
Preliminary trials on female Wistar rats with hydroethanolic extract from "calunga" (Simaba ferruginea St. Hil.) in the gestational stages of implantation, organogenesis and fetal period: interference on offspring. The susceptibility of concepts to chemical agents varies a lot at each development stage. Because of that, most countries started requiring the analysis of potential to affect all aspects of reproduction (spermatogenesis, mating, pregnancy, birth and lactation) for the development of new drugs and herbal medicines. This study aimed to evaluate the effect of the hydroethanolic extract of Simaba ferruginea St. Hil ("calunga") (EHSF) on female Wistar rats treated during pregnancy in order to check the interference on the intrauterine development of the offspring. The rats were treated with EHSF 50 and $100 \mathrm{mg} / \mathrm{kg}^{-1}$ or distilled water, as follows: a) from day 1 to day 6 of pregnancy (period of blastocytes formation and implantation); b) from day 8 to day 16 of pregnancy (embryonic
\end{abstract}

Recebido para publicação em 19/11/2010 
phase of organogenesis); c) from day 15 to day 19 of pregnancy (fetal development phase). The treatment from day 1 to day 6 showed reduction on the amount of fetuses with both doses and it did not alter neither the weight of the uterus / ovary nor the body weight of the mothers. When the female rats were treated in the organogenesis phase, it was verified both statistical significant decrease on the number of live fetuses for the $50 \mathrm{mg} / \mathrm{Kg}^{-1}$, and also appearance of dead fetuses in $30 \%$ of the female rats treated with EHSF $50 \mathrm{mg} / \mathrm{Kg}^{-1}$. In $20 \%$ of the female rats treated with $100 \mathrm{mg} / \mathrm{Kg}^{-1}$, there was no alteration neither in the weight of the uterus / ovary or in the body weight of the matrixes. Finally, the treatment in the fetal period did not affect the number of live descendants, or caused anatomical malformations visible to naked eye and fetal reabsorption. However, $10 \%$ of the mothers treated with $50 \mathrm{mg} / \mathrm{Kg}^{-1}$ presented 2 dead fetuses and $20 \%$ of the mothers who had $100 \mathrm{mg}^{\prime} \mathrm{Kg}^{-1}$ showed, on average, 4 dead fetuses. With this data, we can conclude that EHSF presents low maternal toxicity for Wistar rats, although being fatal to some descendants, not mattering in which pregnancy phase the treatments have been performed, being more evident in the earlier phases. For this reason, it is recommended to avoid the use of this plant in pregnancy case.

Keywords: Simaba ferruginea, rats, pregnancy, offspring, intrauterine.

\section{INTRODUÇÃO}

Os organismos em desenvolvimento sofrem mudanças complexas em curto período de tempo. Consequentemente, a susceptibilidade dos conceptos a agentes químicos varia muito em cada estágio do desenvolvimento. Assim, no período de pré-implantação, a ação de agente tóxico poderá levar a embrioletalidade na fase da organogênese à teratogênese, e a interferência química no final do período gestacional (período fetal) e neonatal poderá ser a intoxicação propriamente dita e/ou carcinogênese (Brinster, 1975; Donadio, 2005). Devido a estes riscos a maioria dos paises passou a exigir que os medicamentos sejam analisados para o potencial de afetar todos os aspectos da reprodução (espermatogênese, acasalamento, gestação, parto e lactação), antes que os mesmos sejam encaminhados para o mercado (Barrow, 1990). No Brasil, estes estudos são regulamentados pela Agencia Nacional de Vigilância Sanitária (ANVISA), Portaria № 116/MS/SNVS, de 8 de agosto de 1996 (Brasil, 1996). A regulamentação despertou interesse em pesquisa neste assunto, e gerou vários trabalhos científicos (Moller et al., 2003; Borges et al., 2005; Brandini et al., 2005; Amaral \& Nunes 2008; Camargo et al., 2009).

A Simaba ferruginea St. Hil. (Simaroubaceae), conhecida como calunga ou felda-terra, é planta nativa do cerrado Mato-grossense, utilizada popularmente para o tratamento de úlceras gástricas, febres, diarréias, dores, inflamações, para emagrecer e para diabete. Está distribuída nas regiões Norte e Centro Oeste do Brasil e na América Central (Marcello, 2001; Lorenzi \& Matos, 2008). Estudos farmacológicos evidenciaram os efeitos anti-ulcerogênicos nos modelos de indução por etanol e indometacina (Marcello, 2001); atividade anti-ulcerogênica e anti-nociceptiva (Noldin, 2005); e atividade antimicrobiana (Silva Junior et al., 2009). Porém, não existem estudos da atividade sobre a prole de mães tratadas durante a prenhez. O presente trabalho objetivou avaliar de modo preliminar o efeito do tratamento de ratas wistar prenhes com extrato hidroetanólico de Simaba ferruginea St. Hil. (EHSF) e a interferência do mesmo no desenvolvimento intra-uterino da prole.

\section{MATERIAL E MÉTODO \\ Coleta e identificação da planta}

Foram coletados rizomas de calunga, Simaba ferruginea St. Hil. (Simaroubaceae) no dia 14/02/2004, em Santo Antônio do Leverger MT, situada $30 \mathrm{Km}$ ao sul de Cuiabá, na Fazenda Experimental da UFMT; altitude: $141 \mathrm{~m}$; latitude: 1547'11"S; longitude: 5604'47"W. A identificação taxonômica foi realizada pelo Professor Dr. Germano Guarim Neto, do Departamento de Botânica e Ecologia do Instituto de Biociências da Universidade Federal de Mato Grosso. Amostras testemunhas do material florífero e herborizado encontram-se depositadas no Herbário Central da Universidade Federal de Mato Grosso, (exsicata no 22591).

\section{Preparo do extrato}

Os rizomas de Simaba ferruginea St. Hil. foram limpos, secos a sombra, em temperatura ambiente e triturados em moinho elétrico. O pó resultante foi pesado e macerado em solução hidroetanólica a 70\% (v/v), na proporção de 1:3 (p/v), por 7 dias ao abrigo da luz e com agitação manual ocasional. Após esse período, os macerados foram filtrados em papel de filtro (no 170g). O filtrado foi submetido à evaporação rotativa, a $45^{\circ} \pm 1^{\circ} \mathrm{C}$, sob pressão reduzida (625 mm Hg), até obtenções dos 
extratos fluidos. Estes foram colocados em estufa a $45^{\circ} \mathrm{C}$, até a completa eliminação do solvente residual. Finalmente, o extrato hidroetanólico de Simaba ferruginea St. Hil (calunga) (EHSF) foi preparado temporariamente por suspensão em água destilada (50 $\mathrm{mg} \mathrm{mL}^{-1}$ ) e utilizado imediatamente dissolvido em água destilada e utilizado nos tratamentos descritos a seguir.

\section{Administração do EHSF a ratas prenhes: consequências na prole}

Ratas de aproximadamente 2 meses e meio de idade e ciclando normalmente por 3 ciclos consecutivos foram colocadas para acasalar com machos sexualmente ativos, em gaiolas de polipropileno $40 \times 50 \times 20 \mathrm{~cm}$ no esquema $1: 3$ (1 macho para 3 fêmeas). O lavado vaginal foi examinado diariamente por microscopia ótica até o aparecimento de espermatozóide ou tampão mucoso na abertura vaginal. Esta constatação delimitava o primeiro dia de prenhez, conforme protocolo de Brito (1994). As fêmeas prenhes foram tratadas com EHSF nas doses de 50 e $100 \mathrm{mg} \mathrm{Kg}^{-1}$ (suspensão 50 mg de EHSF mL-1 em água destilada) e ou água destilada (grupo controle) por via oral através da técnica de gavagem orogástrica uma vez ao dia, seguindo 4 protocolos diferentes:

a) grupos de 10 ratas por dose: controle (água destilada) e tratadas com EHSF 50 ou 100 $\mathrm{mg} \mathrm{Kg}^{-1}$ do $1^{\mathrm{o}}$ ao $6^{\mathrm{o}}$ dia de prenhez (período de pré-implantação e implantação). Durante este período, as ratas eram pesadas diariamente, sempre antes dos tratamentos. No $10^{\circ}$ dia todas foram anestesiadas com éter e feito a laparotomia exploratória, retirando-se o útero / ovário para posterior pesagem e contagem do número de fetos. Em seguida, executava-se a eutanásia por aprofundamento da anestesia;

b) Este grupo contendo de 20 ratas por dose: controle (água destilada) e tratadas com EHSF 50 ou $100 \mathrm{mg} \mathrm{Kg}^{-1}$ do $8^{\circ}$ ao 16으 de prenhez (fase embrionária da organogênese). Neste protocolo, as ratas também foram pesadas diariamente antes dos tratamentos. No $18^{\circ}$ dia de gestação, o grupo foi separado em duas metades: subgrupo b1, 10 ratas por dose, foram mantidas em gaiolas individuais até o parto e após o nascimento, foi feita a contagem do número de filhotes nascidos vivos e a anatomia externa foi examinada em busca de possíveis alterações morfológicas. O subgrupo b2, as 10 ratas restantes de cada dose continuaram agrupadas até o $20^{\circ}$ dia de prenhez, quando foram anestesiadas com éter e foi feita a laparotomia exploratória, retirando o útero / ovário para pesagem e contagem do número de fetos e examinada a anatomia externa. Após este processo, foi feita a eutanásia através do aprofundamento da anestesia com éter. c) Grupos de 10 ratas por dose: controle (água destilada) e tratadas com EHSF 50 ou 100 $\mathrm{mg} \mathrm{Kg}^{-1}$ do $15^{\mathrm{o}}$ ao $19^{\circ}$ dia de prenhez (período fetal). No $20^{\circ}$ dia, as ratas foram anestesiadas com éter e foi feita a laparotomia exploratória, pesandose o útero gravídico e ovários, contando-se os fetos e examinado-se a anatomia externa. Após este processo, foi feita a eutanásia através do aprofundamento da anestesia com éter.

\section{Análise estatística}

Os resultados dos testes paramétricos envolvendo variáveis contínuas foram expressos em e Média \pm Erro Padrão. Para comparação múltipla dos dados paramétricos, foi utilizada a análise de variância (ANOVA) de uma via, seguida Teste de Dunett. Em todas as análises estatísticas, considerou-se o nível crítico para rejeição da hipótese de nulidade $(p<0,05)$ (Snedecor, 1963).

\section{animal \\ Comissão de ética em experimentação}

Este trabalho foi avaliado pela Comissão de Ética da Faculdade de Ciências Médicas da Santa Casa de São Paulo (CEEA), (protocolo no 123, 2006). Os estudos foram realizados de acordo com as normas do Código de Ética Profissional do Médico Veterinário e do Colégio Brasileiro de Experimentação Animal (COBEA).

\section{RESULTADO}

Ratas tratadas com EHSF ou veículo do $1^{\circ}$ ao 6을 dia de prenhez

Neste procedimento, verificou-se o peso corporal e peso úmido do útero / ovário das matrizes e número de fetos.

A Tabela 1 mostra redução estatisticamente significante no número de fetos tanto para a dose de $50 \mathrm{mg} \mathrm{Kg}^{-1}(6,5 \pm 0,1)(\mathrm{p}<0,01)$, quanto para a dose de $100 \mathrm{mg} \mathrm{Kg}^{-1}(5,6 \pm 0,2)(p<0,001)$ em relação ao grupo controle $(10,2 \pm 0,5)$ (Teste de ANOVA seguido de Teste de Dunett).

TABELA 1. Número de fetos de ratas tratadas com EHSF v.o., uma vez ao dia do $1^{\circ}$ ao $6^{\circ}$ dia de prenhez. Dados \pm Erro Padrão.

\begin{tabular}{lc}
\hline Tratamentos & $\begin{array}{c}\text { № de fetos } \\
\text { Média } \pm \text { EPM }\end{array}$ \\
\hline Água destilada & $10,2 \pm 0,5$ \\
EHSF $50 \mathrm{mg} \mathrm{Kg}^{-1}$ & $6,5 \pm 0,1^{* *}$ \\
EHSF $100 \mathrm{mg} \mathrm{Kg}^{-1}$ & $5,6 \pm 0,2^{* * *}$ \\
\hline
\end{tabular}

** $p<0,01$, ${ }^{* * *} p<0,001$ em relação ao grupo controle (água destilada); (ANOVA uma via, seguido do teste de Dunett); № de animais por grupo =10; EHSF (extrato hidroetanólico de Simaba ferruginea St. Hil) 
Em relação ao peso do útero / ovário, o teste de ANOVA não mostrou diferença estatisticamente significante entre o grupo controle $(0,051 \pm 0,0003$ g), e tratados com EHSF $50 \mathrm{mg} \mathrm{Kg}^{-1}(0,051 \pm 0,0004$ g) e $100 \mathrm{mg} \mathrm{Kg}^{-1}(0,046 \pm$ 0,0051 g) (Tabela 2).

Pode ser observado na Tabela 3 que não houve alteração estatisticamente significante na massa corporal das ratas tratadas do $1^{\mathrm{o}}$ ao $6^{\mathrm{o}}$ dia de prenhez com EHSF 50 e $100 \mathrm{mg} \mathrm{Kg}^{-1}$ em relação ao grupo controle (teste de ANOVA).

\section{Ratas tratadas com EHSF ou veículo do $8^{\circ}$ ao $16^{\circ}$ dia de prenhez - cesariana no $20^{\circ}$ dia \\ O tratamento com EHSF do $8^{\circ}$ ao $16^{\circ}$ dia} de prenhez levou à redução na média do número de fetos vivos com a dose de $50 \mathrm{mg} \mathrm{Kg}^{-1}$ (10,1 \pm $2,1)$ quando comparados com o grupo que recebeu água destilada $(11,5 \pm 1,2)(p<0,05)$; porém, não foi observada alteração estatisticamente significante no número de fetos com a dose de $100 \mathrm{mg} \mathrm{Kg}^{-1}$ (10,3 \pm 2,5 ) em relação ao grupo controle (ANOVA de uma via, seguido do teste de Dunett) (Tabela 4).

Pode ser observado na Tabela 5 que 3 ratas (30\%) tratadas com EHSF $50 \mathrm{mg} \mathrm{Kg}^{-1}$ apresentaram feto morto no interior do útero, e com a dose de 100 $\mathrm{mg} \mathrm{Kg}^{-1} 2$ (20\%) também apresentaram mortalidade intra-uterina. Quando foi analisado o número de fetos mortos, constatou-se 1 feto por mãe com a dose de $50 \mathrm{mg} \mathrm{Kg}^{-1}$ e em média 2 fetos por mãe com a dose de $100 \mathrm{mg} \mathrm{Kg}^{-1}$.

Os dados da Tabela 6 mostram que não houve alteração na massa úmida do útero / ovário

TABELA 2. Efeito do EHSF v.o., uma vez ao dia, do $1^{\circ}$ ao $6^{\circ}$ dia de prenhez na massa úmida do útero / ovário de ratas. Dados em Média \pm Erro Padrão.

\begin{tabular}{lc}
\hline Tratamentos & Massa úmida útero/ovário \\
& $(\mathbf{g})$ \\
\hline Água destilada & $0,051 \pm 0,0003$ \\
EHSF $50 \mathrm{mg} \mathrm{Kg}^{-1}$ & $0,051 \pm 0,0004$ \\
EHSF 100 mg Kg-1 & $0,046 \pm 0,0051$ \\
\hline
\end{tabular}

ANOVA uma via; № de animais por grupo = 10; EHSF (extrato hidroetanólico de Simaba ferruginea St. Hil) das ratas tratadas com EHSF 50 e $100 \mathrm{mg} \mathrm{Kg}^{-1}$ do $8^{\circ}$ ao $16^{\circ}$ dia de prenhez $(p>0,05)$ em relação ao grupo controle (teste de ANOVA).

A massa corporal das ratas do subgrupo b1, tratadas com o EHSF do 8o ao 16으 dia de prenhez também não foi alterada de forma estatisticamente significante (teste de ANOVA) (Tabela 7).

Ratas tratadas com EHSF ou veículo do $8^{\circ}$ ao $16^{\circ}$ dia de prenhez - parto natural

Observou-se que as ratas prenhes dos (subgrupos b1 e b2), tratadas com EHSF do $8^{\circ}$ ao $16^{\circ}$ dia de prenhez, apresentaram redução estatisticamente significante no número de filhotes nascidos vivos nas doses de $50 \mathrm{mg} \mathrm{Kg}^{-1}(9,2 \pm 2,8)$ e $100 \mathrm{mg} \mathrm{Kg}^{-1}(9,7 \pm 1,7)$, em relação ao grupo controle $(11,7 \pm 1,0)(p<0,05)$, teste de ANOVA uma via, seguido do teste de Dunett (Tabela 8).

e prenhez. Dados em média \pm Erro Padrão.

\section{Ratas tratadas com EHSF ou veículo do $15^{\circ}$ ao 19ำ dia de gestação}

Pode ser visto na Tabela 9 que quando as ratas foram tratadas com EHSF 50 ou $100 \mathrm{mg} \mathrm{Kg}^{-1}$, do $15^{\circ}$ ao $19^{\circ}$ dia de prenhez, não houve alteração estatisticamente significante no número de filhotes vivos, comparados ao grupo controle. Também não foram observadas malformações na anatomia externa da prole, nem pontos de reabsorção fetal no útero das mães.

Ao analisar o perfil individual das mães constatou-se que $100 \%$ da prole das fêmeas, controle estavam vivos, enquanto que nos animais submetidos ao tratamento com $50 \mathrm{mg} \mathrm{Kg}^{-1}$ de EHSF uma rata $(10 \%)$ apresentou 2 filhotes mortos no interior do útero, e com $100 \mathrm{mg} \mathrm{Kg}^{-1}, 2$ ratas (20\%) apresentaram mortalidade intra-uterina, sendo neste caso o número médio de filhotes mortos foi de 4 por fêmea (Tabela 10).

Finalmente não foram verificadas diferenças estatisticamente significantes nas massas úmidas do útero / ovário das ratas tratadas com água destilada ou EHSF 50 ou $100 \mathrm{mg} \mathrm{Kg}^{-1}$ do $15^{\circ}$ ao 19을

TABELA 3. Efeito do EHSF v.o., uma vez ao dia do $1^{\circ}$ ao $6^{\circ}$ dia de prenhez, no peso corporal de ratas wistar. Dados em Média \pm Erro Padrão (ANOVA uma via).

\begin{tabular}{|c|c|c|c|}
\hline \multirow{3}{*}{ Dias de Tratamento } & \multicolumn{3}{|c|}{ Peso Corporal (g) } \\
\hline & \multicolumn{3}{|c|}{ Tratamentos } \\
\hline & Água destilada & EHSF $50 \mathrm{mg} \mathrm{Kg}^{-1}$ & EHSF $100 \mathrm{mg} \mathrm{Kg}^{-1}$ \\
\hline $1^{\circ}$ & $222 \pm 4.2$ & $230 \pm 1.3$ & $225 \pm 1.9$ \\
\hline $2^{\mathrm{o}}$ & $221 \pm 5.3$ & $228 \pm 3.6$ & $227 \pm 2.6$ \\
\hline $3^{\text {o }}$ & $224 \pm 3.7$ & $227 \pm 3.3$ & $224 \pm 3.7$ \\
\hline $4^{\circ}$ & $225 \pm 2.9$ & $225 \pm 5.7$ & $222 \pm 1.9$ \\
\hline $5^{\mathrm{o}}$ & $230 \pm 4.7$ & $227 \pm 1.7$ & $220 \pm 4.4$ \\
\hline $6^{o}$ & $232 \pm 4.1$ & $229 \pm 3.8$ & $221 \pm 2.5$ \\
\hline
\end{tabular}

№ de animais por grupo = 10; EHSF (extrato hidroetanólico de Simaba ferruginea St. Hil) 
TABELA 4. Número de fetos vivos presentes no útero de ratas tratadas com EHSF ou água destilada v.o., uma vez ao dia do $8^{\circ}$ ao $16^{\circ}$ dia de prenhez (Média \pm Erro Padrão).

\begin{tabular}{lc}
\hline Tratamentos & № de fetos vivos \\
\hline Água destilada & $11,5 \pm 1,2$ \\
EHSF $50 \mathrm{mg} \mathrm{Kg}^{-1}$ & $10,1 \pm 2,1^{*}$ \\
EHSF $100 \mathrm{mg} \mathrm{Kg}^{-1}$ & $10,3 \pm 2,5$ \\
\hline
\end{tabular}

p<0,05 em relação ao grupo controle (água destilada); ANOVA uma via, seguido do teste de Dunett; № de animais por grupo = 10; EHSF (extrato hidroetanólico de Simaba ferruginea St. Hil)

TABELA 5. Frequência de ratas tratadas com EHSF v.o, do $8^{\circ}$ ao $16^{\circ}$ dia de prenhez que apresentaram fetos mortos e número de fetos mortos por matriz.

\begin{tabular}{lcccc}
\hline Tratamentos & № & $\begin{array}{c}\text { № de ratas que } \\
\text { apresentaram fetos } \\
\text { mortos }\end{array}$ & $\begin{array}{c}\text { \% de ratas que } \\
\text { apresentaram fetos } \\
\text { mortos }\end{array}$ & $\begin{array}{c}\text { № de fetos mortos } \\
\text { por matriz }\end{array}$ \\
\hline Água destilada & 10 & 0 & 0 & 0 \\
EHSF 50 mg Kg-1 & 10 & 3 & 30 & 1 \\
EHSF 100 mg Kg-1 & 10 & 2 & 20 & 2 \\
\hline
\end{tabular}

№ = número de ratas por grupo

TABELA 6. Efeito do tratamento de ratas com EHSF v.o., do $8^{\circ}$ ao $16^{\circ}$ dia de prenhez, sobre peso úmido útero / ovário. Dados em Média \pm Erro Padrão.

\begin{tabular}{lc}
\hline Tratamentos & Massa úmida útero / ovário $(\mathbf{g})$ \\
\hline Água destilada & $0,03 \pm 0,0006$ \\
EHSF $50 \mathrm{mg} \mathrm{Kg}^{-1}$ & $0,02 \pm 0,0001$ \\
EHSF $100 \mathrm{mg} \mathrm{Kg}^{-1}$ & $0,02 \pm 0,002$ \\
\hline
\end{tabular}

ANOVA uma via; № de animais por grupo = 10; EHSF (extrato hidroetanólico de Simaba ferruginea St. Hil)

TABELA 7. Efeito do tratamento de ratas do subgrupo b1, com EHSF v.o., do $8^{\circ}$ ao $16^{\circ}$ dia de prenhez, no ganho de peso corpóreo. Dados em Média \pm Erro Padrão.

\begin{tabular}{|c|c|c|c|}
\hline \multirow{3}{*}{ Dias de Tratamento } & \multicolumn{3}{|c|}{ Peso Corporal (g) } \\
\hline & \multicolumn{3}{|c|}{ Tratamentos } \\
\hline & Água destilada & EHSF 50 mg Kg-1 & EHSF $100 \mathrm{mg} \mathrm{Kg}^{-1}$ \\
\hline $8^{\mathrm{o}}$ & $235 \pm 4.2$ & $229 \pm 1.2$ & $233 \pm 1.8$ \\
\hline $10^{\circ}$ & $237 \pm 5.3$ & $233 \pm 2.5$ & $238 \pm 2.4$ \\
\hline $12^{\mathrm{o}}$ & $245 \pm 3.7$ & $239 \pm 3.3$ & $241 \pm 3.6$ \\
\hline $14^{\circ}$ & $251 \pm 2.9$ & $245 \pm 4.6$ & $249 \pm 2.1$ \\
\hline $16^{o}$ & $260 \pm 4.7$ & $253 \pm 1.8$ & $251 \pm 3.8$ \\
\hline $18^{\circ}$ & $263 \pm 4.1$ & $257 \pm 2.9$ & $253 \pm 3.5$ \\
\hline
\end{tabular}

ANOVA uma via; № de animais por grupo = 20; EHSF (extrato hidroetanólico de Simaba ferruginea St. Hil)

TABELA 8. Média do número de filhotes nascidos vivos de ratas tratadas com EHSF v.o., do $8^{\circ}$ ao $16^{\circ}$ dia d

\begin{tabular}{lc}
\hline Tratamentos & oo de filhotes nascidos vivos \\
\hline Água destilada & $11,7 \pm 1,0$ \\
EHSF $50 \mathrm{mg} \mathrm{Kg}^{-1}$ & $9,2 \pm 2,8^{*}$ \\
EHSF $100 \mathrm{~g} \mathrm{Kg}^{-1}$ & $9,7 \pm 1,8^{*}$ \\
\hline
\end{tabular}

* $p<0,05$ em relação ao grupo Água destilada (controle), teste de ANOVA, seguido do teste de Dunett; № de animais por grupo = 10; EHSF (extrato hidroetanólico de Simaba ferruginea St. Hil) 
TABELA 9. Número de fetos vivos no útero de ratas tratadas com EHSF v.o. do $15^{\circ}$ ao $19^{\circ}$ dia de prenhez. Dados em Média \pm Erro Padrão.

\begin{tabular}{|c|c|c|c|}
\hline \multirow{2}{*}{ Tratamentos } & № de filhotes & Malformações & Pontos de reabsorção \\
\hline & MÉDIA \pm EPM & $\mathrm{AE}$ & fetal \\
\hline Água destilada & $11,5 \pm 1,2$ & ausente & ausente \\
\hline EHSF $50 \mathrm{mg} \mathrm{Kg}^{-1}$ & $10,3 \pm 1,8$ & ausente & ausente \\
\hline EHSF $100 \mathrm{mg} \mathrm{Kg}^{-1}$ & $10,1 \pm 1,7$ & ausente & ausente \\
\hline
\end{tabular}

ANOVA uma via; № de animais por grupo = 10; AE (anatomia externa) EHSF (extrato hidroetanólico de Simaba ferruginea St. Hil)

TABELA 10. Frequência de ratas tratadas com EHSF v.o., do $15^{\circ}$ ao $19^{\circ}$ dia de prenhez que apresentaram filhotes mortos, e número de filhotes mortos por matriz após cesariana no $20^{\circ}$ dia de prenhez.

\begin{tabular}{lcccc}
\hline Tratamentos & \multicolumn{2}{c}{$\begin{array}{c}\text { № de ratas que } \\
\text { № }\end{array}$} & $\begin{array}{c}\text { \% de ratas que apresentaram } \\
\text { apresentaram fetos mortos }\end{array}$ & $\begin{array}{c}\text { № de fetos mortos por } \\
\text { matriz }\end{array}$ \\
\hline Água destilada & 10 & 0 & 0 & 0 \\
EHSF $50 \mathrm{mg} \mathrm{Kg}^{-1}$ & 10 & 1 & 10 & 2 \\
EHSF $100 \mathrm{mg} \mathrm{Kg}^{-1}$ & 10 & 2 & 20 & 4 \\
\hline
\end{tabular}

№ = número de ratas

TABELA 11. Efeito do EHSF v.o. $15^{\circ}$ ao $19^{\circ}$ dia de prenhez, na massa úmida útero / ovário de ratas. Dados em Média \pm Erro Padrão.

\begin{tabular}{lc}
\hline Tratamentos & $\begin{array}{c}\text { Massa úmida útero / ovário }(\mathbf{g}) \\
\text { Média } \pm \text { EPM }\end{array}$ \\
\hline Água destilada & $0,042 \pm 0,0012$ \\
EHSF $50 \mathrm{mg} \mathrm{Kg}^{-1}$ & $0,034 \pm 0,0011$ \\
EHSF $100 \mathrm{mg} \mathrm{Kg}^{-1}$ & $0,041 \pm 0,0122$ \\
\hline
\end{tabular}

ANOVA uma via; № de animais por grupo $=10$; EHSF (extrato hidroetanólico de Simaba ferruginea St. Hil)

dia de prenhez, $p>0,05$ teste de ANOVA (Tabela 11).

\section{DISCUSSÃO}

Pode ser observado na Tabela 1 que o tratamento com EHSF 50 e $100 \mathrm{mg} \mathrm{Kg}^{-1}$ do $1^{\circ}$ ao $6^{\circ}$ dia de prenhez reduziu o número de fetos no útero materno. Isto pode estar relacionado com redução na concentração sanguínea de progesterona, pois baixos níveis deste hormônio interferem na viabilidade do embrião, conforme Kato et al. (1979); Galimberti et al. (2001) e Por outro lado, a Tabela 2 mostra que a massa úmida do útero / ovário não foi alterada em nenhum grupo de fêmeas prenhes tratadas com EHSF em relação ao grupo controle.

A massa do ovário constitui uma forma indireta de avaliar o estado progestacional materno, pois o maior componente é formado por corpos lúteos que aumentam de volume ao longo da gestação e são as principais fontes de progesterona conforme Souza et al. (1997). Estes dados enfraquecem a hipótese de que a redução no número de fetos esteja relacionada com a queda da concentração sanguínea de progesterona.

$O$ extrato ainda pode estar interferindo diretamente com a segmentação da célula ovo e, consequentemente, com a formação da blástula (blastocisto), que ocorre do $3^{\circ}$ ao $4^{\circ}$ dia de prenhez em ratas ou dificultando a implantação que ocorre do $4^{\circ}$ ao $5^{\circ}$ dias para esta espécie. Estes eventos são importantes para o estabelecimento da prenhez, conforme Tawafik et al. (1987) e a falha em qualquer um deles pode interferir na efetivação da concepção.

Análise fotoquímica da fração hexânica do extrato de rizoma de Simaba ferruginea St. Hil realizada por Noldin (2005) mostrou a presença dos alcalóides (Cantin-6-ona; 4-metoxicantin-6ona), cujas estruturas químicas são semelhantes a 2-metoxicantin-6-ona (principio ativo presente em outra espécie da família Simaroubaceae) e que tem propriedades de antifertilidade (Njar et al., 1995; Raji \& Bolarinwa, 1997). Além destes alcalóides, Noldin (2005) descreveu em extratos da folha de Simaba ferruginea St. Hil os esteróides estigmasterol e $\beta$-sitosterol. Este último apresenta atividades, antiinflamatória, antibacteriana e antifúngica (Ovesna et al., 2004). Várias outras atividades foram descritas para este esteróide entre elas citotóxicas e estrogênicas. A propriedade estrogênica, poderia estar envolvida com um aumento da motilidade uterina dificultando a implantação do embrião. Por outro lado a citotoxicidade pode levar a morte embrionária. Serão necessários estudos posteriores com as frações do extrato para esclarecer destes dados.

O peso corporal das mães tratadas com EHSF do $1^{\circ}$ ao $6^{\circ}$ dia de prenhez (Tabela 3 ) sofreu variações semelhantes às fêmeas do grupo controle, sugerindo ausência de toxicidade materna. Estes dados estão de acordo com os encontrados por Barros (2007) com as mesmas doses de EHSF, nos 15 dias que antecederam o acasalamento de ratas. 
Este autor também verificou ausência de alteração no consumo alimentar, consumo hídrico, e nas concentrações de uréia, aspartato aminotranferase (AST), proteínas totais, albumina e glicose. Apenas a dose de $100 \mathrm{mg} \mathrm{Kg}^{-1}$ apresentou aumento da alanina aminotransferase (ALT). Assim sendo, estas doses do extrato parecem ter baixa toxicidade para ratas adultas, sendo pouco provável que a toxicidade materna tenha interferindo na redução do número de filhotes implantados.

Quando as fêmeas foram tratadas do $8^{\circ}$ ao $16^{\circ}$ dia de prenhez também foram observadas reduções no número de fetos na tuba uterina com a dose de $50 \mathrm{mg} \mathrm{Kg}^{-1}$ (Tabela 4). Além disso, 3 ratas (30\% das tratadas com EHSF $50 \mathrm{mg} \mathrm{Kg}$. 1), apresentaram fetos mortos no útero, e com a dose de $100 \mathrm{mg} \mathrm{Kg}^{-1}$, e 2 ratas (20\%) também apresentaram mortalidade intra-uterina. Quando foi analisado o número de fetos mortos, constatou-se 1 feto morto por mãe com menor dose e em média 2 fetos por mãe com a maior dose, aparentando ter ocorrido incremento de $100 \%$ no numero de fetos mortos (Tabela 5).

Pode ser visto, na Tabela 8 , redução da prole das fêmeas que tiveram parto normal. Estes dados sugerem uma possível malformação com característica letal, uma vez que o período de tratamento correspondeu à fase da organogênese (Manson \& Kang, 1994)

Conforme a Tabela 6 , o peso do útero / ovário não foi alterado. Estes dados confirmam aqueles encontrados quando as ratas foram tratadas no período de pré-implantação e implantação (Tabela 2).

A média do peso corporal das matrizes também não foi alterado pelo tratamento com nenhuma dose de EHSF do $8^{\circ}$ ao $16^{\circ}$ dia de prenhez, não sendo caracterizada toxicidade materna através deste parâmetro (Tabela 7). Estes dados são semelhantes aos da Tabela 3 e aos obtidos por Barros (2007), e reforça a hipótese de que essas doses de EHSF têm baixa toxicidade para as ratas adultas.

O tratamento com EHSF no período desenvolvimento fetal ( $15^{\circ}$ ao $20^{\circ}$ dia de prenhez), não alterou o número de filhotes nascidos vivos de forma estatisticamente significante, não provocou alterações anatômicas visíveis a olho nu (Tabela 9). Também não foi alterado o peso do útero / ovário (Tabela 11), sugerindo ausência de toxicidade nesta fase do desenvolvimento intra-uterino. Porém, 1 rata $\left(10 \%\right.$ das tratadas com EHSF $\left.50 \mathrm{mg} \mathrm{Kg}^{-1}\right)$, apresentou fetos mortos no útero, e 2 ratas $(20 \%)$ das tratadas com a dose de $100 \mathrm{mg} \mathrm{Kg}^{-1}$ também apresentaram mortalidade intra-uterina. Quando foi analisado o número de fetos mortos, constatou-se 2 fetos por mãe com menor dose e em média 4 fetos por mãe com a maior dose, representando o dobro da mortalidade (Tabela 10). Isto sugere que um ou mais componentes do extrato atravessam a barreira placentária provocando efeitos tóxicos que são letais para os indivíduos mais sensíveis.

\section{CONCLUSÃO}

O EHSF, nas condições experimentais utilizadas, não foi aparentemente tóxico, para ratas adultas, porém reduziu o número de descendentes, independentemente da fase da prenhez em que a mãe foi tratada. Considerando-se o uso popular da mesma, desaconselha-se a utilização desta planta por mulheres grávidas.

\section{REFERÊNCIA}

AMARAL, V.C.S.; NUNES JUNIOR, G.P. Ketoconazoleand fluconazole-induced embryotoxicity and skeletal anomalies in wistar rats: a comparative study. Brazilian Archives of Biology and Technology, v.51, p.115361, 2008.

BARROS, W.M. Efeito do extrato hidroetanólico dos rizomas de Simaba ferruginea ST Hil. (Simabaroubaceae), sobre o comportamento de reprodução de ratas da linhagem Wistar. 2007. 86p. Tese (Doutorado - Curso de Pós-Graduação em Ciências Médicas), Faculdade de Ciências Médicas da Santa Casa de São Paulo, São Paulo.

BARROW, P. Technical procedures in reproduction toxicology. 1.ed. London: Laboratory Animals Ltd., 1990. 55p.

BORGES, L.V. et al. A toxicidade do Hypericum perforatum administrado a ratas prenhes. Revista da Associação Médica Brasileira, v.51, p.206-08, 2005.

BRANDINI, D.A. et al. Effects of cigarette smoke on the Meckel's cartilage of rat fetus: morphologic, morphometric and stereologic study. Brazilian Dental Journal, v.16, p.62-6, 2005.

BRASIL, MINISTÉRIO DASAÚDE, AGÊNCIANACIONAL DE VIGILÂNCIA SANITÁRIA (ANVISA). Portaria № 116/ MS/SNVS de 08 de agosto de 1996. Dispõe Normas para Estudo da Toxicidade e da Eficácia de Produtos Fitoterápicos. Diário Oficial da União, Brasília, 12 agosto, 1996.

BRINSTER, R. Teratogens testing using preimplantation mammalian embryos. In: SHERPARD, T.H.; MILLER, J.R.; MAROIS, M. (Eds.) Methods for detection of environmental agents that produce congenital defects. New York: American Elsevier Plubising Co., 1975. p.113-24.

BRITO, A.S. Manual de ensaios toxicológicos in vivo. Campinas: Editora da Universidade Estadual de Campinas, 1994. 122p.

CAMARGO, I.C.C. et al. Efeitos dos esteróides anabólicos androgênicos sobre o útero e parâmetros reprodutivos de ratas adultas. Revista Brasileira de Ginecologia e Obstetrícia, v.31, p.453-60, 2009.

DONADIO, M.V.F. Efeitos do estresse agudo e participação do sistema angiotensinérgico sobre 
a função reprodutiva em ratas: comportamento sexual, ovulação e lactação. 2005. 124p. Tese (Doutorado - em Ciências Biológicas: Fisiologia) Departamento de Fisiologia da Universidade Federal do Rio Grande do Sul, Porto Alegre.

GALIMBERTI, A.M. et al. Taxa de gestação e níveis plasmáticos de progesterona, em receptoras de embrião bovino, tratadas com buserelina após a inovulação. Revista Brasileira de Zootecnia, v.30, p.353-59, 2001.

KATO, $\mathrm{H}$. et al. Quantitative relationship between the experimentally determined number of conceptuses and corpus luteum activity in pregnant rat. Endocrinology, v.105, p.846-50, 1979.

LORENZI, H.; MATOS, A.F.J. Plantas medicinais no Brasil: nativas e exóticas. 2 Ed. São Paulo Editora do Instituto Plantarum de Estudos da Flora LTDA, 2008. $544 p$

MANSON, J.M.; KANG, Y.J. Test methods for assessing female reproductive and developmental toxicology. In: A. W. Hayes (ed.), Principles and methods of toxicology. 3.ed., New York, Raven Press, 1994. PP 989-1034

MARCELLO, C.M. Triagem antiúlcera de plantas medicinais usadas popularmente em Mato Grosso para afecções gastrointestinais e validação préclínica de Simaba ferruginea St. Hil. (calunga) como antiúlcera. 2001. 125p. Dissertação (Mestrado - Curso de Pós-Graduação em Saúde e Ambiente) Instituto de Saúde Coletiva, Universidade Federal de Mato Grosso, Cuiabá.

MÕLLER, V.M. et al. Efeitos da ivermectina (Ivomec® 1 por cento injetável) administrada a ratas Wistar durante o período de organogênese. Brazilian Journal of Veterinary Research and Animal Science, v.40, p.328-33, 2003

NJAR, V.C. et al. Antifertility activity of Quassia amara: quassin inhibits the steroidogenesis in rat Leydg cells in vitro. Planta Med. v.61, p.180-82, 1995.

NOLDIN, V.F. Estudos fotoquímicos das folhas e rizomas de Simaba ferruginea St. Hil. e avaliação da atividade antiúlcera e antinoceptiva dos extratos e compostos isolados. 2005. 91p. Dissertação (Mestrado em Ciências Farmaceuticas) - Programa de Mestrado Acadêmico em Ciências Farmacêuticas, Universidade do Vale do Itajaí.

OVESNA, Z. et al. Taraxasterol ad beta- sitosterol: new naturally compounds with chemoprotective / chemopreventive effects. Neoplasma, v.51, p.407-14, 2004.

RAJI, Y.; BOLARINWA, A.F. Antifertility activity of Quassia amara in male rats - in vivo stady. Life Sciences, v.61, p.1067-74, 1997.

SILVA JUNIOR, I.E. et al. Triagem antimicrobiana de algumas plantas medicinais do Cerrado de Mato Grosso. Revista Brasileira de Farmacognosia, v.19, p.242-48, 2009.

SNEDECOR, G.W. Statistical methods. Lowa, State University Press Ames, 1963. 482p.

SOUZA, E.R.; GUERRA, M.O.; PETERS, V.M. Desenvolvimento de pré-embriões de ratas Wistar da colônia do Biotério do Centro de Biologia da Reprodução. Boletim do Centro de Biologia da Reprodução UFJF, v.16, 63-70, 1997.

TAWAFIK, O.W. et al. Release of prostaglandins and leukotrienes from the rat uterus is an estrogenic response. Prostaglandins, v.34, p.805-15, 1987. 